\title{
Effect of calcium hydroxide dressing on microleakage of composite restorations in endodontically treated teeth subsequent to bleaching
}

\author{
Saeed Rahimi ${ }^{1}$, Shahriar Shahi ${ }^{1}$, Soodabeh Kimyai ${ }^{2}$, Lali Khayyam ${ }^{3}$, Majid Abdolrahimi ${ }^{3}$ \\ ${ }^{1}$ DDS, MS. Associate Professor. Department of Endodontics \\ ${ }^{2}$ DDS, MS. Associate Professor. Department of Operative Dentistry, School of Dentistry, Tabriz University of Medical Sciences, \\ Tabriz, Iran \\ ${ }^{3}$ DDS
}

Correspondence:

Department of Operative Dentistry

Tabriz University of Medical Sciences, $\quad$ Rahimi S, Shahi S, Kimyai S, Khayyam L, Abdolrahimi M. Effect of School of Dentistry

Gholghasht Street, Zip: 5166614713

Tabriz, Iran

kimyais@tbzmed.ac.ir

\begin{abstract}
calcium hydroxide dressing on microleakage of composite restorations in endodontically treated teeth subsequent to bleaching. Med Oral Patol Oral Cir Bucal. 2010 Mar 1;15 (2):e413-6.
\end{abstract}

http://www.medicinaoral.com/medoralfree01/v15i2/medoralv15i2p413.pdf

Received: 19/05/2009 Accepted: 02/08/2009

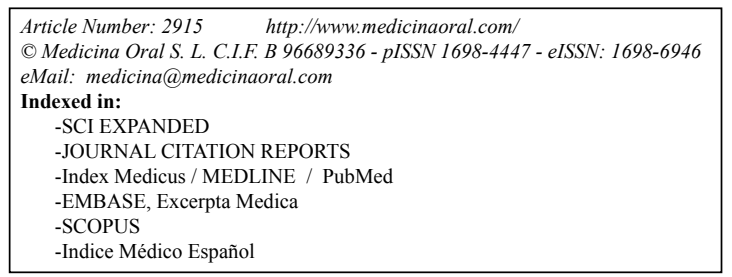

\begin{abstract}
Objective: This study evaluates the effect of calcium hydroxide dressing on microleakage of composite restorations following non-vital bleaching. Methods: A total of 45 sound extracted human maxillary central incisors underwent endodontic treatment. The teeth were randomly divided into three groups $(n=15)$. In group 1 , access cavities were restored with composite. In group 2, the teeth underwent a bleaching procedure for one week before being restored with composite. In group 3, following a bleaching procedure, calcium hydroxide paste was placed in the pulp chamber for one week. The teeth were then restored with composite. The specimens were subjected to a dye leakage test. The data was analyzed using Kruskal-Wallis and Mann-Whitney U tests. Results: There were significant differences between the groups $(\mathrm{P}<0.0005)$. No statistically significant differences were found between groups 2 and 3, while the differences between other groups were significant. Conclusions: The bleaching agent increased microleakage of composite restorations in non-vital bleaching, whereas microleakage was not found to be increased by calcium hydroxide.
\end{abstract}

Key words: Calcium hydroxide, composite restorations, laboratory research, microleakage, non-vital bleaching.

\section{Introduction}

Intra-coronal bleaching agents have been used successfully to bleach endodontically treated teeth $(1,2)$. Conventionally, $30 \%$ hydrogen peroxide alone, or along with heat or in combination with sodium perborate, is used to bleach root canal treated teeth $(2,3)$. Despite the effectiveness of $30 \%$ hydrogen peroxide for tooth bleaching, external root resorption is a complication of the material $(4,5)$.
Placement of calcium hydroxide $\left[\mathrm{Ca}(\mathrm{OH})_{2}\right]$ dressing in the pulp chamber is one of the methods to decrease the possibility of external root resorption (1). It increases environmental $\mathrm{pH}$, resulting in a decrease in osteoclastic activity; therefore, the resorptive process is prevented $(1,6)$. Despite various advantages attributed to calcium hydroxide, its role in microleakage of composite restorations has not been fully elucidated and it is believed that its remnants on access cavity walls lead to increased 
microleakage of composite restorations (1), which can cause color changes and bacterial penetration (7). Considering the limited number of studies on the influence of $\mathrm{Ca}(\mathrm{OH})_{2}$ on microleakage, the aim of the present study was to evaluate the effect of $\mathrm{Ca}(\mathrm{OH})_{2}$ as a temporary dressing on microleakage of composite restorations subsequent to non-vital bleaching.

\section{Materials and Methods}

The specimens consisted of 45 sound extracted human maxillary central incisors. The teeth were stored in $0.5 \%$ chloramin $\mathrm{T}$ solution. They had been extracted for periodontal reasons and did not have any resorptions, decalcifications and fractures mesiodistally and buccolingually as evidenced by periapical radiographs.

Round diamond burs (SS White Burs, Lakewood Inc, USA) were used for access cavity preparation. Working length was determined by introducing a \#10 K-file (Dentsply, Maillefer, Ballaigues, Switzerland) into each canal until the file tip was visible at the apex; working length was determined $1 \mathrm{~mm}$ short of this measured length. After introduction of hand files and establishment of a glide path, RaCe files (FKG Dentaire, Switzerland) were used to clean and shape the root canals. During preparation and between each file, $1 \mathrm{~mL}$ of $0.5 \%$ sodium hypochlorite was used as an irrigant. The canals were all prepared to a $\mathrm{RaCe} \# 35,0.04$ file. After completion of instrumentation all the canals were dried with paper points and filled with gutta-percha (Diadent, Cheongchong Buk Do, Korea) and AH26 root canal sealer (Dentsply, GmbH, Konstanz, Germany) using lateral condensation technique. Radiographs were provided to make sure that the canals had been properly obturated. Then a hot plugger was used to remove $3 \mathrm{~mm}$ of gutta-percha from the coronal third of each canal, later to be sealed with light-cured glass-ionomer (Fuji II LC, GC, Tokyo, Japan).

The teeth were randomly divided into three groups of 15 teeth each. In group 1 (control), dry cotton pellets were placed in the pulp chamber and the cavity was sealed with self-curing glass-ionomer (Fuji II, GC, Tokyo, Japan) for seven days. After seven days, the glassionomer cement was removed with a round carbide bur (SS White) in a high-speed handpiece. Then the pulp chamber was irrigated with normal saline. The access cavity and the pulp chamber were etched with $35 \%$ phosphoric acid (Scotchbond Etchant, 3M ESPE, Dental Products, St, Paul, MN, USA) for 15 seconds according to manufacturer's instructions and then rinsed with water spray. Bonding agent (Single Bond, 3M ESPE) was used according to manufacturer's instructions. Then the access cavity was restored with $\mathrm{A} 3$ shade of composite resin (Z100, 3M ESPE) using the incremental technique. Astralis 7 light-curing unit (Ivoclar Vivadent, FL-9494 Schaan, Liechtenstein) was used to light-cure the restorations. An 8-mm-diameter probe was used for curing, which was placed perpendicular to the surface of restoration adjacent to it (40 seconds for each increment). The restorations were polished after 24 hours using diamond polishing burs (Diamant Gmbh, D \& Z, Goerzallee, Berlin, Germany) and polishing disks (Sof-LexTM, 3M ESPE). Then the specimens were immersed in distilled water and kept in an incubator at $37^{\circ}$ $\mathrm{C}$ for a week.

In the second group the same procedure as described for group 1 was carried out except for the fact that $30 \%$ hydrogen peroxide gel (Opalescence Extra, Ultradent Products. Inc, USA) was placed in the pulp chamber and was sealed with self-curing glass-inomer (Fuji II) for one week. The specimens were kept in an incubator at $37^{\circ} \mathrm{C}$ in distilled water for a week; subsequently a round carbide bur (SS White) in a high-speed handpiece was used to remove glass-ionomer. The bleaching agent was removed with a spoon excavator. The access cavities were restored in the same manner as described for group 1 after irrigation with water.

In the third group glass-ionomer and the bleaching agent were removed in the same manner as described after the bleaching procedure; then the pulp chamber was filled with $\mathrm{Ca}(\mathrm{OH})_{2}$ (Produits Dentaires S.A, Vevey, Switzerland). Finally the access cavity was sealed with selfcuring glass-ionomer. After one week of incubation in distilled water at $37^{\circ} \mathrm{C}$ glass-ionomer was removed with a carbide bur in a high-speed handpiece and $\mathrm{Ca}(\mathrm{OH})_{2}$ was removed by irrigation; then the access cavities were restored in the same manner as described for group 1. Prior to the evaluation of microleakage, the teeth were subjected to a thermocycling procedure of 500 cycles at $5 \pm 2^{\circ} \mathrm{C} / 55 \pm 2^{\circ} \mathrm{C}$ in a water bath with a dwell time of 30 seconds and a transfer time of 10 seconds. The apex of each tooth was sealed with utility wax and all tooth surfaces were painted with two layers of nail varnish except for the restoration and $1 \mathrm{~mm}$ around the restoration. Then the teeth were immersed in India ink for 72 hours and then rinsed under tap water. The teeth were buccolingually divided at the center of the restoration using a diamond disk (Diamant Gmbh, D \& Z). Finally the specimens were evaluated by two observers under a stereomicroscope (Nikon, Tokyo, Japan) at magnification $\times 20$.

The following grading system was used for microleakage evaluation:

Grade 0: No dye penetration.

Grade I: Dye penetration only into the enamel.

Grade II: Dye penetration into the enamel and dentin (8).

Kruskal-Wallis test was used to compare microleakage between groups and Mann-Whitney U test was used for the two-by-two comparison of the groups. Statistical significance was defined at $\mathrm{P}<0.05$. 


\section{Results}

Microleakage grades are shown in Table 1. The results of Kruskal-Wallis test demonstrated statistically significant differences in microleakage between the groups $(\chi 2=21.13, \mathrm{df}=2, \mathrm{P}<0.0005)$. Two-by-two comparison of the groups demonstrated statistically significant differences between groups 1 and 2, and groups 1 and 3 $(\mathrm{P}<0.0005$ and $\mathrm{P}=0.001$, respectively); however, no statistically significant differences were observed between groups 2 and $3(\mathrm{P}=0.29)$.

Table 1. Microleakage grades in the groups.

\begin{tabular}{|c|c|c|c|}
\hline \multirow{2}{*}{ Groups } & \multicolumn{3}{|c|}{ Microleakage grades } \\
\cline { 2 - 4 } & $\mathbf{0}$ & I & II \\
\hline 1 & 5 & 7 & 3 \\
\hline 2 & 0 & 1 & 14 \\
\hline 3 & 0 & 3 & 12 \\
\hline
\end{tabular}

\section{Discussion}

Increased microleakage of composite restorations subsequent to non-vital bleaching can jeopardize the longterm success of the bleaching procedure and endodontic treatment (3).

The use of hydrogen peroxide as a bleaching agent is the most important factor in inducing external root resorption among bleaching agents $(9,10)$, because of its low $\mathrm{pH}$ and producing an acidic environment (11). Moreover, it increases the dentinal permeability to microorganisms subsequent to bleaching which might have a role in external root resorption (5). Therefore, hydrogen peroxide was used in this study.

Methylene blue and India ink are widely used for the evaluation of microleakage in root canal treated teeth (12). In the present study India ink was preferred to methylene blue because calcium hydroxide can decolorize methylene blue $(13,14)$. Therefore, the results won't be reliable.

The results of this study showed that non-vital bleaching with hydrogen peroxide leads to increased microleakage of composite restorations, which is consistent with the results of a previous study (1). One of the reasons for increased microleakage might be decreased bond strength of composite resin to tooth structure immediately after bleaching procedure (15). Studies using electron microscope have demonstrated changes in composite bonding to tooth structure: resin tags were shorter in bleached teeth compared to non-bleached teeth and were less abundant; the quality and quantity of resin tags are important factors in composite bond strength $(16,17)$. Furthermore, increased microleakage might be attributed to peroxide remnants and remaining reactive oxygen species in tooth structure which can in- terfere with the penetration of resin into tooth structure and resin polymerization $(1,8)$. In addition, tooth structural changes following bleaching procedures, including changes in organic and mineral components of tooth structure, denaturing of proteins, decrease in calcium concentration, and decreased tooth strength have been reported as factors involved in reduced bond strength of composite resins to tooth structure (18).

According to this study, the use of calcium hydroxide subsequent to bleaching (group 3) did not result in increased microleakage compared to group 2, in which calcium hydroxide was not used after bleaching; these results do not coincide with the results of a previous study (1), according to which use of calcium hydroxide after bleaching not only did not increase microleakage compared to a group in which calcium hydroxide was not used, but it decreased microleakage to the level of that in the control group in which neither bleaching had been carried out nor calcium hydroxide had been used. The differences between the results of that study and ours might be attributed to different dyes used in these two studies: Demarco et al. (1) used methylene blue whereas we used India ink. Since calcium hydroxide can decolorize methylene blue (13) it can be presumed that in that study in the group in which calcium hydroxide had been used subsequent to bleaching less microleakage might have been observed compared to the group in which calcium hydroxide had not been used.

Previous studies which have attempted to evaluate the effect of intra-canal calcium hydroxide remnants on apical seal $(19,20)$ have concluded that calcium hydroxide significantly increases apical microleakage; the discrepancies between the results of those studies and the present study might be attributed to the difficulty of removing calcium hydroxide remnants from canals compared to removing them from the pulp chamber. Despite great efforts to remove calcium hydroxide remnants from the canals very fine remnants are trapped in the canals and influence microleakage.

Within the limitations of this study it was concluded that the use of $30 \%$ hydrogen peroxide resulted in increased microleakage of composite restorations following nonvital bleaching procedure while the use of calcium hydroxide did not increase microleakage of composite restorations subsequent to non-vital bleaching.

\section{References}

1. Demarco FF, Freitas JM, Silva MP, Justino LM. Microleakage in endodontically treated teeth: influence of calcium hydroxide dressing following bleaching. Int Endod J. 2001;34:495-500.

2. Friedman S. Internal bleaching: long-term outcomes and complications. J Am Dent Assoc. 1997;128 Suppl:51S-55S.

3. Türkün M, Türkün LS. Effect of nonvital bleaching with $10 \%$ carbamide peroxide on sealing ability of resin composite restorations. Int Endod J. 2004;37:52-60.

4. Heller D, Skriber J, Lin LM. Effect of intracoronal bleaching on external cervical root resorption. J Endod. 1992;18:145-8.

5. Heling I, Parson A, Rotstein I. Effect of bleaching agents on dentin 
permeability to Streptococcus faecalis. J Endod. 1995;21:540-2. 6. Tronstad L, Andreasen JO, Hasselgren G, Kristerson L, Riis I. pH changes in dental tissues after root canal filling with calcium hydroxide. J Endod. 1981;7:17-21.

7. Hervás-García A, Martínez-Lozano MA, Cabanes-Vila J, Barjau-Escribano A, Fos-Galve P. Composite resins. A review of the materials and clinical indications. Med Oral Patol Oral Cir Bucal. 2006;11:E215-20.

8. Teixeira EC, Hara AT, Turssi CP, Serra MC. Effect of non-vital tooth bleaching on microleakage of coronal access restorations. J Oral Rehabil. 2003;30:1123-7.

9. Friedman S, Rotstein I, Libfeld H, Stabholz A, Heling I. Incidence of external root resorption and esthetic results in 58 bleached pulpless teeth. Endod Dent Traumatol. 1988;4:23-6.

10. Abou-Rass M. Long-term prognosis of intentional endodontics and internal bleaching of tetracycline-stained teeth. Compend Contin Educ Dent. 1998;19:1034-8, 1040-2,1044.

11. Rotstein I, Friedman S. pH variation among materials used for intracoronal bleaching. J Endod. 1991;17:376-9.

12. Veríssimo DM, Do Vale MS. Methodologies for assessment of apical and coronal leakage of endodontic filling materials: a critical review. J Oral Sci. 2006;48:93-8.
13. Wu MK, Kontakiotis EG, Wesselink PR. Decoloration of $1 \%$ methylene blue solution in contact with dental filling materials. J Dent. 1998;26:585-9.

14. Calişkan MK, Sen BH. Endodontic treatment of teeth with apical periodontitis using calcium hydroxide: a long-term study. Endod Dent Traumatol. 1996;12:215-21.

15. Stokes AN, Hood JA, Dhariwal D, Patel K. Effect of peroxide bleaches on resin-enamel bonds. Quintessence Int. 1992;23:769-71. 16. Titley KC, Torneck CD, Smith DC, Chernecky R, Adibfar A. Scanning electron microscopy observations on the penetration and structure of resin tags in bleached and unbleached bovine enamel. J Endod. 1991;17:72-5.

17. Dishman MV, Covey DA, Baughan LW. The effects of peroxide bleaching on composite to enamel bond strength. Dent Mater. 1994;10:33-6.

18. Cavalli V, Arrais CA, Giannini M, Ambrosano GM. High-concentrated carbamide peroxide bleaching agents effects on enamel surface. J Oral Rehabil. 2004;31:155-9.

19. Contardo L, De Luca M, Bevilacqua L, Breschi L, Di Lenarda R. Influence of calcium hydroxide debris on the quality of endodontic apical seal. Minerva Stomatol. 2007;56:509-17.

20. Kim SK, Kim YO. Influence of calcium hydroxide intracanal medication on apical seal. Int Endod J. 2002;35:623-8. 